Article

\title{
Electrical Defect State Distribution in Single Crystal ZnO Schottky Barrier Diodes
}

\author{
Jinhee Park ${ }^{1, \dagger}$, You Seung Rim ${ }^{2, \dagger}$, Pradeep Senanayake ${ }^{3}$, Jiechen $\mathrm{Wu}^{1}$ and Dwight Streit ${ }^{1, *}$ \\ 1 Department of Materials Science and Engineering, University of California, \\ Los Angeles, CA 90095, USA; jinhee5park@ucla.edu (J.P.); jiechenwu1988@gmail.com (J.W.) \\ 2 School of Intelligent Mechatronics Engineering, Sejong University, Seoul 05006, Korea; \\ youseung@sejong.ac.kr \\ 3 Department of Electrical Engineering, University of California, Los Angeles, CA 90095, USA; \\ pradeepnuwan@gmail.com \\ * Correspondence: streit@ucla.edu \\ + These authors equally contributed to this work.
}

Received: 19 December 2019; Accepted: 24 February 2020; Published: 27 February 2020

\begin{abstract}
The characterization of defect states in a hydrothermally grown single crystal of $\mathrm{ZnO}$ was performed using deep-level transient spectroscopy in the temperature range of 77-340 K. The native intrinsic defect energy level within the $\mathrm{ZnO}$ band gap occurred in the depletion region of $\mathrm{ZnO}$ Schottky barrier diodes. A major defect level was observed, with a thermal activation energy of $0.27 \mathrm{eV}$ (E3) within the defect state distribution from 0.1 to $0.57 \mathrm{eV}$ below the conduction band minimum. We confirmed the maximum defect concentration to be $3.66 \times 10^{16} \mathrm{~cm}^{-3}$ at $0.27 \mathrm{eV}$ (E3). As a result, we clearly confirmed the distribution of density of defect states in the $\mathrm{ZnO}$ band gap.
\end{abstract}

Keywords: Zinc oxide; Schottky Barrier Diode; DLTS; defect analysis

\section{Introduction}

Zinc oxide has attracted a lot of interest recently, due to its direct and wide band gap $(3.4 \mathrm{eV}$ at $300 \mathrm{~K})$, high mobility, and simple processing, which make it suitable for optical applications such as light-emitting diodes (LEDs), and as a channel material for thin-film transistors (TFTs) in flat-panel displays [1-4]. While $\mathrm{ZnO}$ has a great deal of potential as a candidate for many optical applications, the electrical role of native defects in $\mathrm{ZnO}$ (e.g., $\mathrm{Zn}$ interstitial $\left(\mathrm{Zn}_{\mathrm{i}}\right), \mathrm{Zn}$ vacancy $\left(V_{\mathrm{Zn}}\right)$ and oxygen vacancy $\left.\left(V_{0}\right)\right)$ still remains unclear. It is also difficult to control the electrical defect properties and understand the exact mechanisms of carrier transport, which are associated with a complex defect distribution [5]. Native defects could extensively affect the electrical and optical properties of $\mathrm{ZnO}$-based electronic devices. In particular, the role of defect distribution has been widely examined using photoluminescence (PL) [6], electron paramagnetic resonance (EPR) [7], admittance spectroscopy (AS) [8], and deep level transient spectroscopy (DLTS) [9-12].

Among these techniques, DLTS has a high sensitivity and is suitable for the analysis of defect states and impurities using Schottky diodes or $\mathrm{p}-\mathrm{n}$ junction devices [13]. Therefore, the electronic defect states of $\mathrm{ZnO}$ have been intensively investigated using DLTS to find the evidence of intrinsic conductivity and the role of defect states. One of the most dominant defect states in n-type $\mathrm{ZnO}$ is the well-known $V_{0}$ due to the relatively low formation energy of $3.5 \mathrm{eV}$. Recently, $V_{0}$ has turned out to be a deep donor rather than a shallow donor [5]. Therefore, the origin of intrinsic n-type conductivity in undoped $\mathrm{ZnO}$ is believed not to be $V_{0}$. However, there is not a consensus regarding the source of the intrinsic n-type conductivity in undoped $\mathrm{ZnO}$. Moreover, the explicit role of the defect states has not been fully explained, especially regarding the defect state distribution. 
Up to now, very few papers have addressed the identity of defect states [9,14,15]. Additionally, none of these have confirmed the defect state distribution within the $\mathrm{ZnO}$ band gap. In this work, we have clearly confirmed the defect state distribution under the conduction band minimum (CBM) in the $\mathrm{ZnO}$ band gap. A summary of the prominent defect properties observed in $\mathrm{ZnO}$ using DLTS is shown in Table 1, compared with our result in the end row. In our method, we applied boiling $\mathrm{H}_{2} \mathrm{O}_{2}$ (prior to metal deposition) on the $\mathrm{Zn}$-face (0001) of hydrothermally grown single-crystal $\mathrm{ZnO}$, with $\mathrm{Pd}$ Schottky contacts to improve the Schottky contacts [8,16-19]. DLTS measurements were employed to investigate the defect state distribution. Defect energy levels with E3 $(0.27-0.30 \mathrm{eV})$ and E4 $(0.53 \mathrm{eV})$ in the $\mathrm{ZnO}$ Schottky barrier diodes (SBDs) have been confirmed in previous literature [20-23]. The major defect state of $\mathrm{E} 3(0.27 \mathrm{eV})$ below the CBM was also observed in our $\mathrm{Pd} / \mathrm{ZnO}$ SBDs from the variations of the transient capacitance slope.

Table 1. Literature survey of the electronic properties of prominent defects investigated by deep level transient spectroscopy (DLTS) in as-grown $\mathrm{ZnO}$; the defect energy level $\left(E_{\mathrm{t}}\right)$, defect concentration $\left(N_{\mathrm{t}}\right)$, capture cross section $\left(\sigma_{\mathrm{n}}\right)$ and oxygen vacancy $\left(V_{0}\right)$.

\begin{tabular}{ccccc}
\hline Growth & $\mathbf{E}_{\mathbf{c}}-\mathbf{E}_{\mathbf{t}} \mathbf{( e V )}$ & $\mathbf{N}_{\mathbf{t}}\left(\mathbf{c m}^{-3}\right)$ & $\left.\boldsymbol{\sigma}_{\mathbf{n}} \mathbf{( c m}^{\mathbf{2}}\right)$ & Defect Identity $($ Year) \\
\hline Hydrothermal [14] & 0.278 & $2.1 \times 10^{12}$ & $0.3 \times 10^{-14}$ & singly ionized V 0, donor-like (1988) \\
Vapor-phase [13] & 0.290 & $1.0 \times 10^{14}$ & $5.8 \times 10^{-16}$ & maybe acceptor-like (2001) \\
Hydrothermal [9] & 0.280 & $7.0 \times 10^{14}$ & $4.0 \times 10^{-16}$ & maybe acceptor-like (2011) \\
Melt at high pressure [9] & 0.280 & $3.5 \times 10^{15}$ & $4.0 \times 10^{-16}$ & N/A (2011) \\
Hydrothermal & 0.270 & $3.66 \times 10^{16}$ & $1.36 \times 10^{-16}$ & This work \\
\hline
\end{tabular}

\section{Experimental Methods}

A hydrothermally grown single crystal of bulk $\mathrm{ZnO}$ with the (0001) $\mathrm{Zn}$ face up was used in this experiment. The $\mathrm{Zn}$ face has a lower amount of surface defect concentrations than the $\mathrm{O}$ face, which allows for a higher Schottky barrier height [18]. The carrier concentration, mobility, and resistivity of $\mathrm{ZnO}$ were measured at $0.86 \times 10^{17} \mathrm{~cm}^{-3}, 91.9 \mathrm{~cm}^{2} \cdot \mathrm{V}^{-1} \cdot \mathrm{s}^{-1}$, and $0.85 \Omega \cdot \mathrm{cm}$, respectively, through Hall effect measurements using the van der Pauw geometry (sample size of $10 \times 10 \times 5 \mathrm{~mm}^{3}$ ).

The samples were cleaned in an ultrasonic bath with acetone, isopropyl alcohol (IPA), and de-ionized (DI) $\mathrm{H}_{2} \mathrm{O}$, sequentially. Before the metallization, the samples were placed into a boiling solution of $30 \% \mathrm{H}_{2} \mathrm{O}_{2}$ for 3 min to improve the quality of the Schottky contacts, based on previous reports [8,19,23], and were blown using $\mathrm{N}_{2}$ gas. As shown in Figure 1, annular ohmic contacts (inside diameter $=550 \mu \mathrm{m}$, outside diameter $=800 \mu \mathrm{m})$ and Schottky contacts $($ diameter $450 \mu \mathrm{m})$ were formed on the $\mathrm{ZnO}$ surface via electron-beam evaporation (base pressure of $\sim 10^{-6} \mathrm{mbar}$ ) and lift-off photolithography. Ti/Al/Pt/Au (20/80/40/80 nm) and Pd $(60 \mathrm{~nm})$ were deposited as ohmic and Schottky contacts, respectively [24]. The samples were then annealed at $200{ }^{\circ} \mathrm{C}$ for 1 min under an $\mathrm{N}_{2}$ atmosphere. The Schottky contact area was $1.59 \times 10^{-3} \mathrm{~cm}^{2}$.

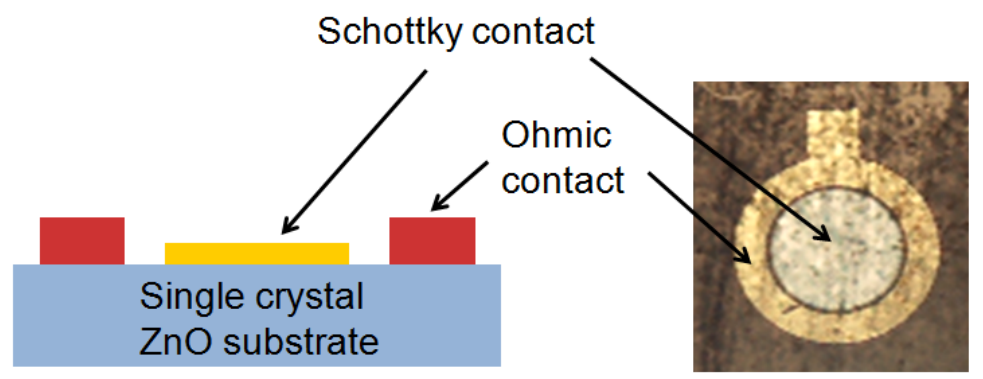

(a)

(b)

Figure 1. (Color Online) Simplified schematic illustration of the Pd/ZnO Schottky Barrier Diode (SBD): (a) Cross sectional view, (b) Top view (optical microscope image). Pd and Ti/Al/Pt/Au are used as Schottky and ohmic contacts, respectively. 
Current-voltage $(\mathrm{I}-\mathrm{V})$, capacitance-voltage $(\mathrm{C}-\mathrm{V})$, and DLTS measurements were performed on the $\mathrm{Pd} / \mathrm{ZnO}$ SBDs. The I-V and C-V measurements were carried out in the dark at room temperature using an Agilent 4156C Precision Semiconductor Parameter Analyzer, and an Agilent E4980A LCR meter. For the $\mathrm{C}-\mathrm{V}$ measurement, the bias voltage was applied from 0 to $-3 \mathrm{~V}$, at $1 \mathrm{MHz}$. The measurement and data extraction of the DLTS (FT1030 DLTS, PhysTech GmbH, Moosburg, Germany) were followed in a previous report [13].

\section{Results and Discussion}

Figure 2 shows the I-V curve of the Pd/ZnO SBD. In order to form improved Schottky contacts on $\mathrm{ZnO}$, a Schottky metal contact (e.g., $\mathrm{Au}, \mathrm{Ag}$, $\mathrm{Pt}$, and $\mathrm{Pd}$ ) on $\mathrm{ZnO}$ is required. However, the Schottky contact behavior of $\mathrm{ZnO}$ does not follow the work function difference directly due to unexpected surface defect states $[5,16,17]$. To overcome this problem, several techniques have been applied to the $\mathrm{ZnO}$ surface, such as oxygen plasma treatment, organic solvent cleaning and hydrogen peroxide $\left(\mathrm{H}_{2} \mathrm{O}_{2}\right)$ treatment $[8,18]$. Among these treatments, the $\mathrm{H}_{2} \mathrm{O}_{2}$ treatment led to the surface defects of $\mathrm{ZnO}$ being significantly eliminated and the Schottky contacts between $\mathrm{ZnO}$ and metal being improved $[8,19]$.

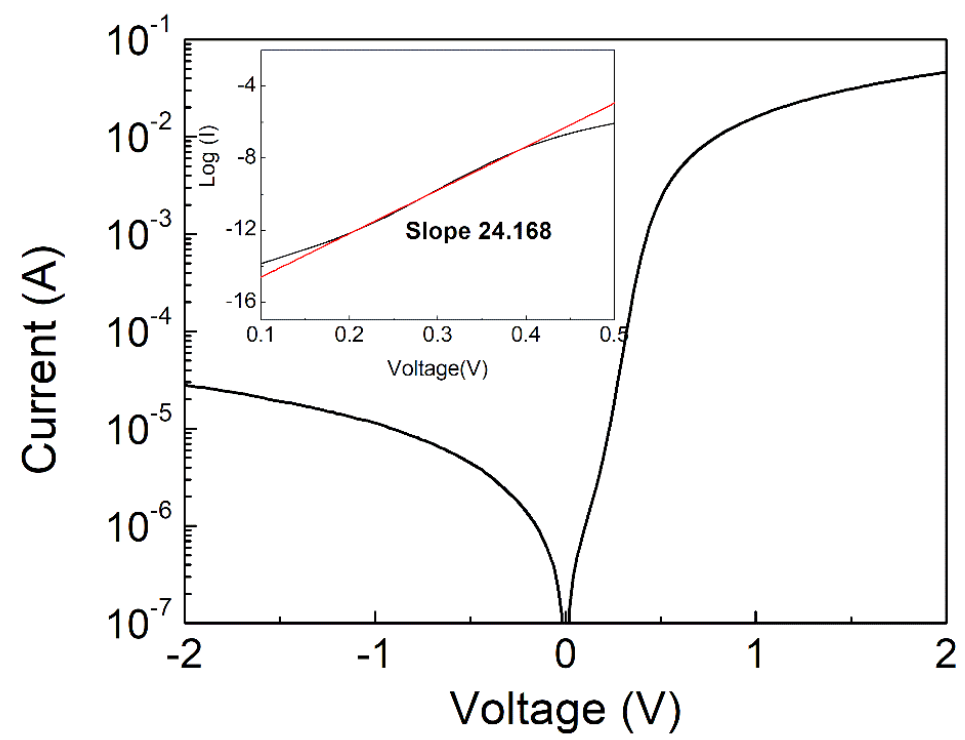

Figure 2. (Color Online) $\mathrm{I}-\mathrm{V}$ characteristics of the $\mathrm{Pd} / \mathrm{ZnO}$ SBDs from -3 to $2 \mathrm{~V}$ at room temperature. Ideality factor $(\mathrm{n})$ is shown in the inset.

The leakage current was $2.8 \times 10^{-5} \mathrm{~A}$ with a reverse bias of $-2.5 \mathrm{~V}$ at room temperature. The leakage current was rectified over $10^{3}$, and reached $4.61 \times 10^{-2} \mathrm{~A}$ at $2 \mathrm{~V}$. Rectifying behavior was clearly shown in the Pd/ZnO SBDs. Typically, the calculation of the Schottky barrier height in diodes can be conducted using both $\mathrm{I}-\mathrm{V}$ and $\mathrm{C}-\mathrm{V}$ techniques, which are important to evaluate the diode performance. To calculate the Schottky barrier height in our devices, the saturation current $\left(I_{\mathrm{s}}\right)$ can be applied to the following equation [25]:

$$
I_{\mathrm{S}}=\mathrm{AA}^{*} \mathrm{~T}^{2} \exp \left(\frac{-\mathrm{O}_{\mathrm{B}}}{\mathrm{kT}}\right)
$$

where $A, A^{*}$, and $\varnothing_{B}$ represent the Schottky contact area $\left(0.00159 \mathrm{~cm}^{2}\right)$, the effective Richardson constant, and the Schottky barrier height, respectively. The theoretical value of $\mathrm{A}^{*}$ in $\mathrm{ZnO}$ is $32 \mathrm{~A} \cdot \mathrm{cm}^{-2} \cdot \mathrm{K}^{-2}$ based on an effective mass $\left(\mathrm{m}^{*}\right)$ of $0.27 \mathrm{~m}_{0}[5]$. The barrier height is calculated from $I_{\mathrm{S}}\left(1.6 \times 10^{-7} \mathrm{~A}\right)$ at a zero bias from Equation (1). $I_{\mathrm{s}}$ was determined by extrapolating the curve of $\ln [\mathrm{I} /(1-\exp (-\mathrm{qV} / \mathrm{kT}))]$ versus voltage under a forward bias up to $\mathrm{V}=0 \mathrm{~V}$. The calculated $\varnothing_{\mathrm{B}}$ of our device was $0.85 \mathrm{eV}$, consistent with previous reports [18].

The ideality factor $(\mathrm{n})$ is plotted by using the $\ln [I /(1-\exp (-\mathrm{qV} / \mathrm{kT}))]$ versus voltage curve as shown in the inset of Figure 2, and $n$ is extracted from the slope of this curve for the evaluation of the 
diode performance [25]. The current-voltage relationship for a Schottky diode can be expressed as $I=I o[\exp (\mathrm{qV} / \mathrm{nkT})-1] \approx I \mathrm{o}{ }^{*} \exp (\mathrm{qV} / \mathrm{nkT})$, and gives $\ln (I)=\ln (\mathrm{Io})+\mathrm{qV} / \mathrm{nkT}$. Therefore, in this plot of $\ln (\mathrm{I})$ vs. $\mathrm{V}$, the slope $(\partial V / \partial I)$ can be extracted, and the ideality factor is calculated using the below equation. Here, we extracted the value of 1.49 in the linear region. This could be attributed to the carrier recombination, tunneling, or the interfacial layer between the metal and the semiconductor $[5,26]$.

Figure 3 shows the $\mathrm{C}-\mathrm{V}$ characteristics of the Pd/ZnO SBDs. We considered two factors, with built-in potential $\left(\mathrm{V}_{\mathrm{bi}}\right)$ and carrier concentration $\left(\mathrm{N}_{\mathrm{d}}\right)$ evaluated as follows: an approximate evaluation of $\mathrm{V}_{\mathrm{bi}}$ was obtained using the intercept of the $1 / \mathrm{C}^{2}$ versus voltage plot, and $\mathrm{N}_{\mathrm{d}}$ was also calculated from the slope of this plot $(a)$. $\mathrm{N}_{\mathrm{d}}$ was obtained using $2 /\left(\mathrm{q} \varepsilon \varepsilon_{\mathrm{o}} a\right)$, where $\mathrm{q}, \varepsilon$, and $\varepsilon_{\mathrm{o}}$ represent the elementary charge, the static dielectric constant ( 8.5 for $\mathrm{ZnO}$ ), and the vacuum permittivity, respectively [25]. The calculated $\mathrm{V}_{\mathrm{bi}}$ of the $\mathrm{Pd} / \mathrm{ZnO}$ SBDs was $0.77 \mathrm{eV}$. Moreover, the carrier concentration of $\mathrm{ZnO}$ is $2.0 \times 10^{17} \mathrm{~cm}^{-3}$, which is similar to the value obtained using Hall effect measurements $\left(0.86 \times 10^{17} \mathrm{~cm}^{-3}\right)$. The Schottky barrier height was in turn obtained using the following equation [25]:

$$
\varnothing_{\mathrm{B}}=\mathrm{q}\left[\mathrm{V}_{\mathrm{bi}}+\frac{\mathrm{kT}}{\mathrm{q}} \ln \left(\frac{\mathrm{N}_{\mathrm{c}}}{\mathrm{N}_{\mathrm{d}}}\right)\right]
$$

where $\mathrm{N}_{\mathrm{c}}$ is the effective density of states of $\mathrm{ZnO}$ in the conduction band $\left(2.94 \times 10^{18} \mathrm{~cm}^{-3}\right.$ using $\left.N_{\mathrm{c}}=2\left(2 \pi \mathrm{m}^{*} \mathrm{kT} / \mathrm{h}^{2}\right)^{3 / 2}\right)$. The $\varnothing_{\mathrm{B}}$ of our Pd/ZnO SBDs turned out to be $0.863 \mathrm{eV}$. The values of the Schottky barrier height showed very similar results, regardless of the measurement methods, which indicates that the Pd Schottky contact on $\mathrm{ZnO}$ was formed successfully. The detailed Schottky properties of the $\mathrm{Pd} / \mathrm{ZnO}$ SBDs are listed in Table 2.

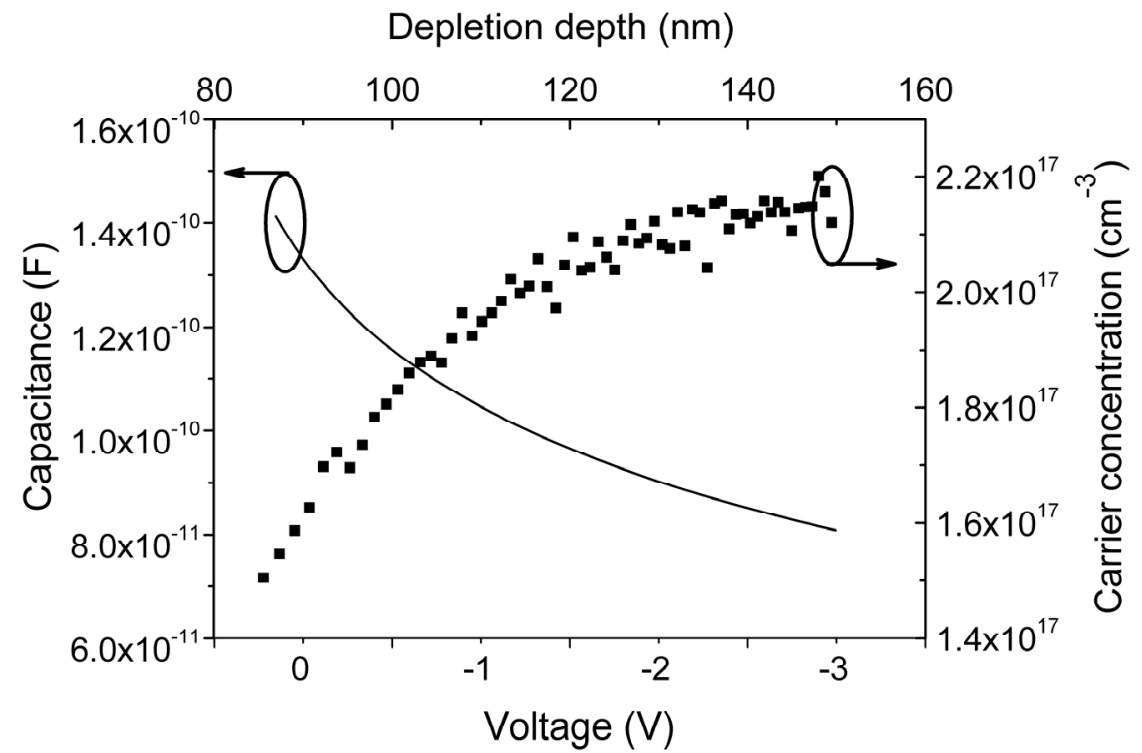

Figure 3. $\mathrm{C}-\mathrm{V}$ characteristics of the $\mathrm{Pd} / \mathrm{ZnO}$ SBDs as a function of reverse bias at $1 \mathrm{MHz}$. Carrier concentration versus depletion width is also plotted.

Table 2. The extracted parameters of the $\mathrm{Pd} / \mathrm{ZnO}$ SBDs at room temperature: the ideality factor (n), reverse current $\left(I_{\text {rev }}\right)$, barrier heights $\left(\varnothing_{\mathrm{B}}\right)$, built-in voltage $\left(V_{\mathrm{bi}}\right)$ and carrier density $\left(N_{\mathrm{d}}\right)$.

\begin{tabular}{ccccccc}
\hline Schottky Metal & $\mathbf{n}$ & $\mathbf{I}_{\text {rev }}$ at $-\mathbf{1} \mathbf{~ V ~ ( A ) ~}$ & $\boldsymbol{Ø}_{\mathrm{B}, \mathrm{I}-\mathrm{V}}(\mathbf{e V})$ & $\boldsymbol{\emptyset}_{\mathrm{B}, \mathrm{C}-\mathrm{V}}(\mathrm{eV})$ & $\mathbf{V}_{\mathbf{b i}}(\mathrm{V})$ & $\mathbf{N}_{\mathrm{d}, \mathrm{C}-\mathrm{V}}\left(\mathrm{cm}^{-\mathbf{3}}\right)$ \\
\hline $\mathrm{Pd}$ & 1.49 & $1.14 \times 10^{-5}$ & 0.85 & 0.86 & 0.77 & $2.0 \times 10^{17}$ \\
\hline
\end{tabular}

For the defect analysis of $\mathrm{ZnO}$, we carried out DLTS measurements for the different temperature ranges from 77 to $340 \mathrm{~K}$ at a frequency of $1 \mathrm{MHz}$. Applied reverse bias voltage was used at $-2.5 \mathrm{~V}$ to form of a strong depletion region and forward bias voltage was then applied at $0 \mathrm{~V}$ with a filling pulse 
time width $\left(t_{\mathrm{p}}\right)$ of $50 \mathrm{~ms}$, as shown in Figure 4a. The transient capacitance was measured to within $40 \mathrm{~ms}$ at different temperatures from 77 to $340 \mathrm{~K}$ (corresponding to $0.1-0.57 \mathrm{eV}$ below the conduction band $\left.\left(E_{\mathrm{c}}\right)\right)$. The maximum transient capacitances were extracted by using different emission rates $\left(e_{\mathrm{n}}\right)$ (emission rate $=\ln \left(\mathrm{t}_{1} / \mathrm{t}_{2}\right) /\left(\mathrm{t}_{2}-\mathrm{t}_{1}\right)$, where $\mathrm{t}_{1}$ and $\mathrm{t}_{2}$ are the start and end of the time window), and emission rates of $0.034,0.042,0.093,0.423$, and $0.888 \mathrm{~ms}^{-1}$ were selected as shown in Figure $4 \mathrm{~b}$. In addition, emission rates $\left(e_{n}\right)$ can also be determined using the equation below [25]:

$$
\mathrm{e}_{\mathrm{n}} / \mathrm{T}^{2}=\gamma_{\mathrm{n}} \sigma_{\mathrm{n}} \times \exp \left(-\left(\left(\mathrm{E}_{\mathrm{c}}-\mathrm{E}_{\mathrm{t}}\right) / \mathrm{KT}\right)\right)
$$

with $\gamma_{\mathrm{n}}=\left(\gamma_{\mathrm{th}} / \mathrm{T}^{1 / 2}\right)\left(\mathrm{N}_{\mathrm{c}} / \mathrm{T}^{3 / 2}\right)=3.25 \times 10^{21}\left(\mathrm{~m}_{\mathrm{n}} / \mathrm{m}_{\mathrm{O}}\right) \mathrm{cm}^{-2} \cdot \mathrm{s}^{-1} \cdot \mathrm{K}^{-2}$, where $\mathrm{m}_{\mathrm{n}}$ is the electron density of-states effective mass and $\mathrm{m}_{\mathrm{O}}$ is the electron rest mass. At different settings of $t_{1}$ and $t_{2}$, the DLTS signal gave out a different set of emission rates for the different temperatures. By using an Arrhenius plot of $\ln \left(e_{\mathrm{n}} / \mathrm{T}^{2}\right)$ vs. $1 / \mathrm{T}$, the trap energy level $\left(E_{\mathrm{t}}\right)$ and capture cross-section $\left(\sigma_{\mathrm{n}}\right)$ were obtained. The Arrhenius plot had a slope of $-\left(E_{\mathrm{c}}-E \mathrm{t}\right) / \mathrm{K}$, determining $E_{\mathrm{t}}$, and an intercept on the $\ln \left(\mathrm{e}_{\mathrm{n}} / \mathrm{T}^{2}\right)$ axis of $\ln \left(\gamma_{n} \sigma_{n}\right)$, determining $\sigma_{n}$. We calculated the defect energy level $\left(E_{t}\right)$ and capture cross section $\left(\sigma_{n}\right)$ by using the Arrhenius plot as shown in Figure 4c. Therefore, we confirmed that the $E_{t}$ and $\sigma_{n}$ of $\mathrm{ZnO}$ were $\mathrm{E}_{\mathrm{c}}-0.27 \mathrm{eV}$ (labeled E3) and $1.36 \times 10^{-16} \mathrm{~cm}^{2}$, respectively $[9,20]$. It is well known that $\mathrm{ZnO}$ has various defect energy levels originating from non-stoichiometry (e.g., $\mathrm{Zn}_{\mathrm{i}}, \mathrm{V}_{\mathrm{Zn}}, \mathrm{Oxygen}$ antisite $\left(\mathrm{O}_{\mathrm{Zn}}\right.$ or $\left.V_{0}\right)$, etc.) [27-30].
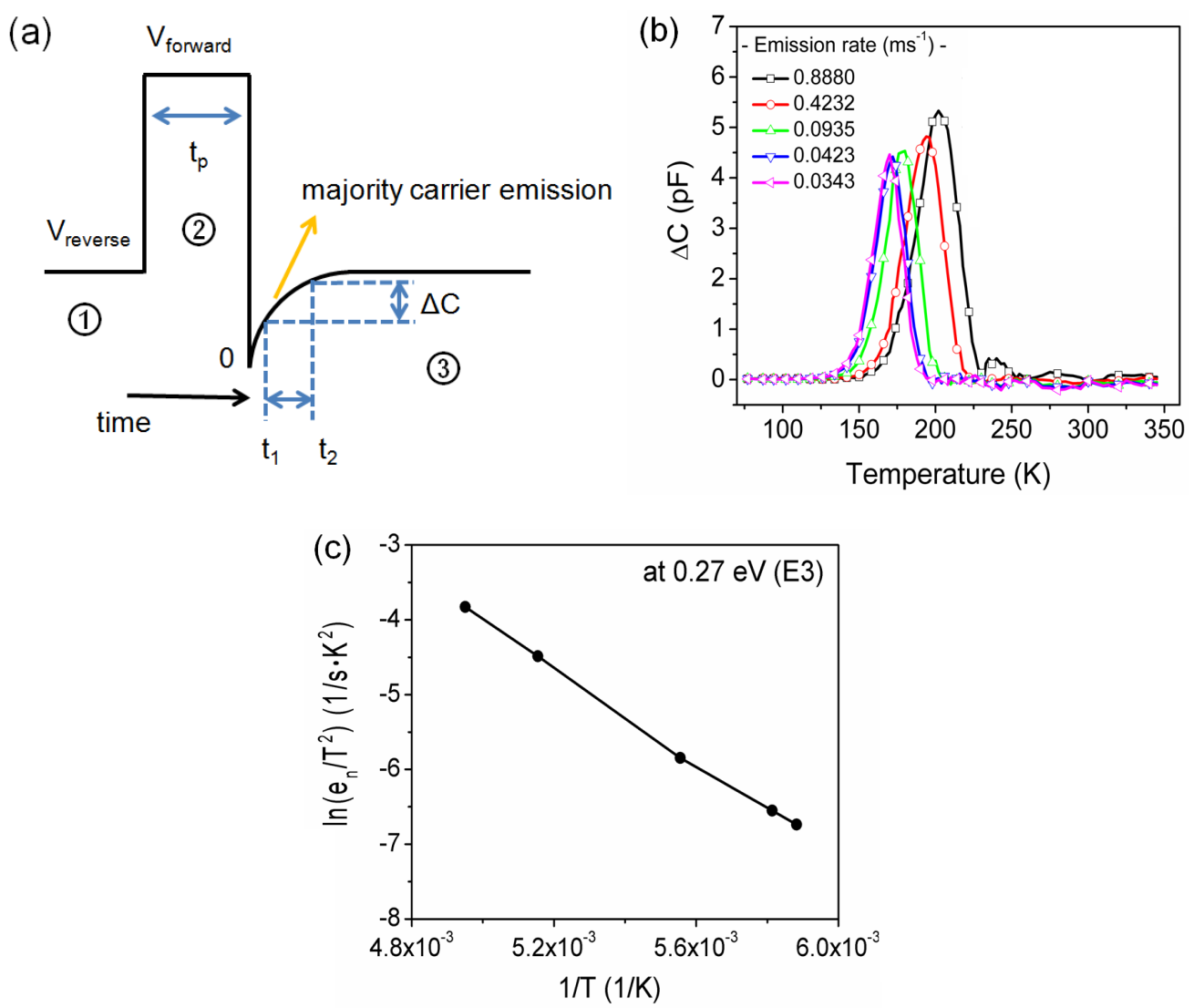

Figure 4. (Color online) (a) Applied voltage and resultant transient capacitance; (b) DLTS spectra of the $\mathrm{Pd} / \mathrm{ZnO}$ SBDs samples under different emission rates from $0.0343 \mathrm{~ms}^{-1}\left(\mathrm{t}_{1}=20.2 \mathrm{~ms}, \mathrm{t}_{2}=40.4 \mathrm{~ms}\right)$ to $0.8880 \mathrm{~ms}^{-1}\left(t_{1}=0.78 \mathrm{~ms}, t_{2}=1.56 \mathrm{~ms}\right)$; (c) Arrhenius plot of the level E3.

This transient capacitance behavior may have been caused by the positively charged defects through the thermal emission of carriers in the depletion region, and by decreased depletion width due to the increase in total charge density, as shown in Figure 5a-c. This is because the donor-type 
defect is positively ionized when it is unoccupied and neutral when it is filled with an electron [25]. In this manner, the signal gives out a different set of emission rates and temperatures. The trap emits carriers at this emission rate. As a result, transient capacitance was increased. This phenomenon is in agreement with those obtained from previous reports [27,31]. However, the origin of these defects is still unclear and complex. It requires further study to find the precise evidence of the defect formation.

(a)

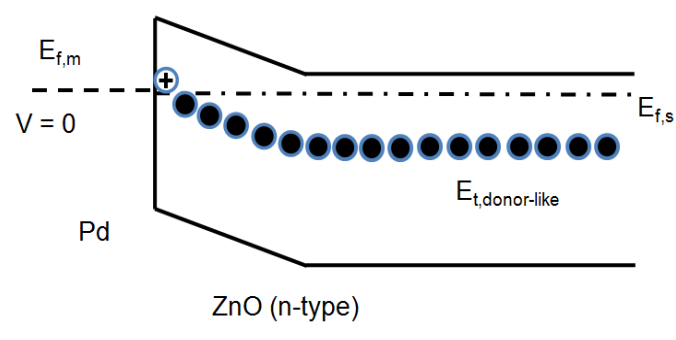

(b)

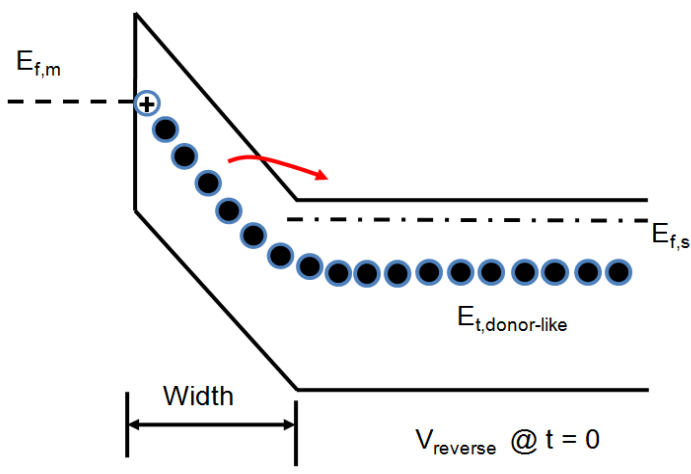

(c)

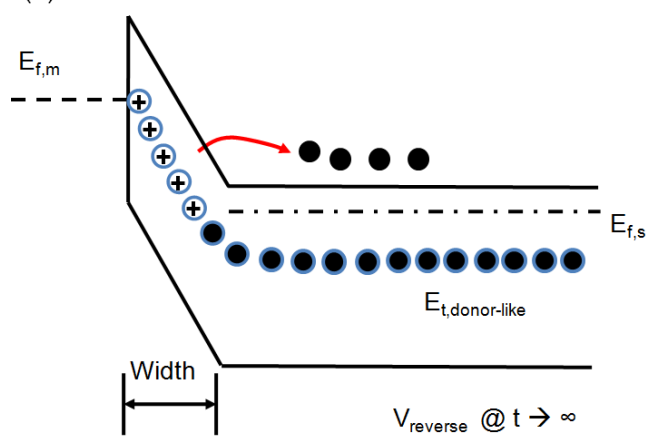

Figure 5. (Color online) A Schottky diode for majority carrier emission; (a) zero bias (forward bias),

(b) reverse bias at $\mathrm{t}=0,(\mathbf{c})$ reverse bias as $\mathrm{t} \rightarrow \infty$.

Typically, both interface and bulk-trap states can contribute to the DLTS signal in a Schottky junction. Although it was difficult to extract only the bulk traps, due to the overlapping of the electron emissions from the interface states $\left(\sim 10^{14} \mathrm{~cm}^{-2}\right)$, the interface state density was much weaker than that of the bulk defect states $\left(\sim 10^{17} \mathrm{~cm}^{-3}\right)$ [32]. Therefore, the predominant defect formation could be defined within the bulk ZnO. Based on DLTS of the Pd/ZnO SBDs, we clearly observed the change of the transient capacitance from 77 to $340 \mathrm{~K}$ and predicted the defect states' distribution between 0.1 and $0.57 \mathrm{eV}$ below the CBM.

The DLTS signal reflects the distribution of the signal originated from each defect energy level. Hence, the DLTS signal is simply proportional to the defect concentration $\left(N_{t}\right)$ given by the equation [13,25]:

$$
N_{\mathrm{t}}=2 N_{\mathrm{d}} \frac{\Delta C_{\max }}{C_{0}}
$$

where $N_{\mathrm{d}}, \Delta C_{\max }$, and $C_{0}$ represent the carrier concentration, maximum transient capacitance amplitude, and capacitance of the device at $-2.5 \mathrm{~V}\left(\mathrm{C}_{0}=85 \mathrm{pF}\right)$, respectively. The temperature range from 77 to $340 \mathrm{~K}$ can also be related to the defect energy level from 0.1 to $0.57 \mathrm{eV}$ below the CBM, and the defect distribution can be calculated by the electron emission rate equation $[13,25,30,33]$ :

$$
E_{\mathrm{c}}-E_{\mathrm{t}}=k T \ln \left(\sigma_{\mathrm{n}} v_{\mathrm{th}} N_{\mathrm{c}} \tau_{0}\right)
$$


where $\mathrm{kT}, \sigma_{\mathrm{n}}, v_{\mathrm{th}}$, and $\tau_{0}$ represent the thermal energy, electron capture cross-section area of the trap (assumed to be $10^{-16} \mathrm{~cm}^{2}$ ), electron thermal velocity, and emission time constant approximated to be half of the time width used in the measurements $\left(\tau_{0}=20 \mathrm{~ms}\right)$, respectively [33]. Calculated defect concentration and distribution are shown in Figure 6. Scattering and noise within the data seemed to be due to thermal instability. We confirmed the maximum defect concentration to be $3.66 \times 10^{16} \mathrm{~cm}^{-3}$ at $0.27 \mathrm{eV}$ from the CBM.

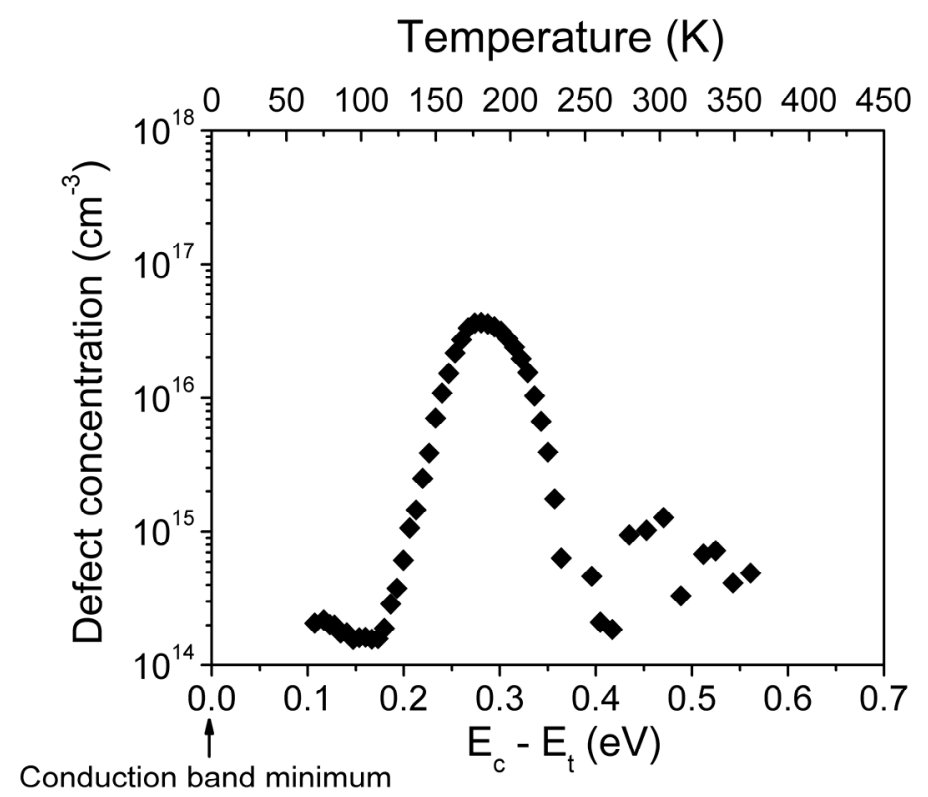

Figure 6. (Color online) The correspondent subgap density of states as a function of defect energy from the conduction band.

\section{Conclusions}

We investigated single-crystal ZnO SBDs and carried out a DLTS analysis to find the defect state distribution in the $\mathrm{ZnO}$ band gap. We confirmed that a Schottky barrier height of $0.85 \mathrm{eV}$ with a Pd contact was formed on the Pd/ZnO SBDs. Compared to previous reports, our ZnO SBDs have a similar defect energy level of $E_{c}-0.27 \mathrm{eV}$ below the CBM. Although the origin of defects is still unclear and more studies are needed, we believe that complex oxygen-related defects could possibly be the source of defects near the conduction band of single crystal ZnO (in the Pd/ZnO SBDs). Finally, we successfully obtained a defect state distribution below the conduction band in the range of 0.1-0.57 eV. The maximum defect concentration was $3.66 \times 10^{16} \mathrm{~cm}^{-3}, 0.27 \mathrm{eV}$ from the CBM.

Author Contributions: Conceptualization, writing, and experiments J.P. and Y.S.R.; methodology and analysis, P.S., J.W.; supervision and editing, D.S. All authors have read and agreed to the published version of the manuscript.

Funding: Financial support was provided by the University of California, Los Angeles (UCLA) school of engineering, Samsung, and Basic Science Research Program through the National Research Foundation of Korea (NRF), funded by the Ministry of Education (2017R1D1A1B03030818).

Acknowledgments: J.H. Park and Y.S. Rim equally contributed to this work. Financial support was provided by the University of California, Los Angeles (UCLA) school of engineering and Samsung. We would also like to thank the Nanoelectronics Research Facility (NRF), acknowledge the use of the Integrated Systems Nanofabrication Cleanroom (ISNC) at the California NanoSystems Institute (CNSI) in UCLA, and thank the Basic Science Research Program through the National Research Foundation of Korea (NRF), funded by the Ministry of Education (2017R1D1A1B03030818), for making the fabrication of this device possible. Special thanks to Alan Farrell and Diana Huffaker for their support.

Conflicts of Interest: The authors declare no conflict of interest. 


\section{References}

1. Jagadish, C.; Pearton, S.J. Zinc Oxide Bulk, Thin Films and Nanostructures: Processing, Properties, and Applications, 1st ed.; Elsevier: Oxford, UK, 2006.

2. Wager, J.F. Transparent electronics. Science 2003, 300, 1245-1246. [CrossRef]

3. Fortunato, E.; Barquinha, P.; Pimentel, A.; Goncalves, A.; Marques, A.; Pereira, L.; Martins, R. ACMBG Pi-mentel, AMF Goncalves, AJS Marques and LMN Pereira. Adv. Mater. 2005, 17, 590. [CrossRef]

4. Monakhov, E.V.; Kuznetsov, A.Y.; Svensson, B.G. Zinc oxide: Bulk growth, role of hydrogen and Schottky diodes. J. Phys. D: Appl. Phys. 2009, 42, 153001. [CrossRef]

5. $\quad$ Özgür, Ü.; Alivov, Y.I.; Liu, C.; Teke, A.; Reshchikov, M.A.; Doğan, S.; Avrutin, V.; Cho, S.J.; Morkoç, H. A comprehensive review of ZnO materials and devices. J. Appl. Phys. 2005, 98, 041301. [CrossRef]

6. Zeuner, A.; Alves, H.; Hofmann, D.M.; Meyer, B.K.; Heuken, M.; Bläsing, J.; Krost, A. Structural and optical properties of epitaxial and bulk ZnO. Appl. Phys. Lett. 2002, 80, 2078. [CrossRef]

7. Hofmann, D.M.; Hofstaetter, A.; Leiter, F.; Zhou, H.; Henecker, F.; Meyer, B.K.; Orlinskii, S.B.; Schmidt, J.; Baranov, P.G. Hydrogen: A relevant shallow donor in zinc oxide. Phys. Rev. Lett. 2002, 88, 045504. [CrossRef]

8. Schifano, R.; Monakhov, E.V.; Grossner, U.; Svensson, B.G. Electrical characteristics of palladium Schottky contacts to hydrogen peroxide treated hydrothermally grown ZnO. Appl. Phys. Lett. 2007, 91, 193507. [CrossRef]

9. Scheffler, L.; Kolkovsky, V.I.; Lavrov, E.V.; Weber, J. Deep level transient spectroscopy studies of n-type ZnO single crystals grown by different techniques. J. Phys.: Condens. Matter 2011, 23, 334208. [CrossRef]

10. Chicot, G.; Muret, P.; Santailler, J.-L.; Feuillet, G.; Pernot, J. Oxygen vacancy and EC- 1 eV electron trap in ZnO. J. Phys. D: Appl. Phys. 2014, 47, 465103. [CrossRef]

11. Gür, E.; Coşkun, C.; Tüzemen, S. High energy electron irradiation effects on electrical properties of $\mathrm{Au} / \mathrm{n}-\mathrm{ZnO}$ Schottky diodes. J. Phys. D: Appl. Phys. 2008, 41, 105301. [CrossRef]

12. Ohbuchi, Y.; Kawahara, T.; Okamoto, Y. Morimoto, Distributions of Interface States and Bulk Traps in ZnO Varistors. J. Jpn. J. Appl. Phys. 2011, 40, 213. [CrossRef]

13. Lang, D.V. Fast capacitance transient appartus: Application to $\mathrm{ZnO}$ and $\mathrm{O}$ centers in $\mathrm{GaP}$ p-n junctions. J. Appl. Phys. 1974, 45, 3023. [CrossRef]

14. Auret, F.D.; Goodman, S.A.; Hayes, M.; Legodi, M.J.; Laarhoven, H.A.V.; Look, D.C. The influence of high energy proton bombardment on the electrical and defect properties of single-crystal ZnO. J. Phys.: Condens. Matter. 2001, 13, 8989.

15. Rucavado, E.; Jeangr, Q.; Urban, D.F.; Holovský, J.; Remes, Z.; Duchamp, M.; Landucci, F.; Dunin-Borkowski, R.E.; Körner, W.; Elsässer, C.; et al. Enhancing the optoelectronic properties of amorphous zinc tin oxide by subgap defect passivation: A theoretical and experimental demonstration. Phys. Rev. B 2017, 95, 245204. [CrossRef]

16. Sheng, H.; Muthukumar, S.; Emanetoglu, N.W.; Lu, Y. Schottky diode with Ag on (1120) epitaxial ZnO film. Appl. Phys. Lett. 2002, 80, 2132. [CrossRef]

17. Allen, M.W.; Alkaisi, M.M.; Durbin, S.M. Metal Schottky diodes on Zn-polar and O-polar bulk ZnO. Appl. Phys. Lett. 2006, 89, 103520. [CrossRef]

18. Brillson, L.J.; Lu, Y. ZnO Schottky barriers and Ohmic contacts. J. Appl. Phys. 2011, 109, 121301. [CrossRef]

19. Schifano, R.; Monakhov, E.V.; Svensson, B.G.; Diplas, S. Surface passivation and interface reactions induced by hydrogen peroxide treatment of n-type $\mathrm{ZnO}(000$ 1). Appl. Phys. Lett. 2009, 94, 132101. [CrossRef]

20. Fang, Z.-Q.; Claflin, B.; Look, D.C.; Dong, Y.F.; Mosbacker, H.L.; Brillson, L.J. Surface traps in vapor-phase-grown bulk $\mathrm{ZnO}$ studied by deep level transient spectroscopy. J. Appl. Phys. 2008, 104, 063707. [CrossRef]

21. Auret, F.D.; Nel, J.M.; Hayes, M.; Wu, L.; Wesch, W.; Wendler, E. Electrical characterization of growth-induced defects in bulk-grown ZnO. Superlatt. Microstruct. 2006, 39, 17. [CrossRef]

22. Vines, L.; Monakhov, E.V.; Svensson, B.G. Effect of high temperature treatments on defect centers and impurities in hydrothermally grown ZnO. Physica B 2009, 404, 4386. [CrossRef]

23. Gu, Q.L.; Ling, C.C.; Chen, X.D.; Cheng, C.K.; Ng, A.; Beling, C.D.; Fung, S.; Djurišić, A.B.; Lu, L.W.; Brauer, G.; et al. Hydrogen peroxide treatment induced rectifying behavior of $\mathrm{Au} / \mathrm{n}-\mathrm{Zn} \mathrm{O}$ contact. Appl. Phys. Lett. 2007, 90, 122101. [CrossRef] 
24. Ip, K.; Thaler, G.T.; Yang, S.; Han, H.S.; Li, Y.; Norton, D.P.; Pearton, S.J.; Jang, S.F.; Ren, J. Contacts to ZnO. Cryst. Growth 2006, 287, 149. [CrossRef]

25. Schroder, D.K. Semiconductor Material and Device Characterization, 3rd ed.; John Wiley \& Sons, Inc.: Hoboken, NJ, USA, 2006.

26. Sze, S.M.; Ng, K.K. Physics of Semiconductor Devices., 3rd ed.; John Wiley \& Sons, Inc.: Hoboken, NJ, USA, 2007.

27. Janotti, A. and Van de Walle, C.G. Native point defects in ZnO. Phys. Rev. B 2007, 76, 165202. [CrossRef]

28. Kohan, A.F.; Ceder, G.; Morgan, D.; Van de Walle, C.G. First-principles study of native point defects in ZnO. Phys. Rev. B 2000, 61, 15019. [CrossRef]

29. Janotti, A.; Van de Walle, C.G. Oxygen vacancies in ZnO. Appl. Phys. Lett. 2005, 87, 122102. [CrossRef]

30. Janotti, A.; Van de Walle, C.G. Fundamentals of zinc oxide as a semiconductor. Rep. Prog. Phys. 2009, 72, 126501. [CrossRef]

31. Look, D.C.; Hemsky, J.W.; Sizelove, J.R. Residual native shallow donor in ZnO. Phys. Rev. lett. 1999, 82, 2552. [CrossRef]

32. Brillson, L.J. Semiconductors and Semimetals: Oxide Semiconductors, 1st ed.; Svensson, B.G., Pearton, S.J., Eds.; SEMSEM; Academic Press: San Diego, CA, USA, 2013.

33. Chasin, A.; Simoen, E.; Bhoolokam, A.; Nag, M.; Genoe, J.; Gielen, G.; Heremans, P. Deep-level transient spectroscopy on an amorphous $\mathrm{InGaZnO}_{4}$ Schottky diode. Appl. Phys. Lett. 2014, 104, 082112. [CrossRef]

(C) 2020 by the authors. Licensee MDPI, Basel, Switzerland. This article is an open access article distributed under the terms and conditions of the Creative Commons Attribution (CC BY) license (http://creativecommons.org/licenses/by/4.0/). 